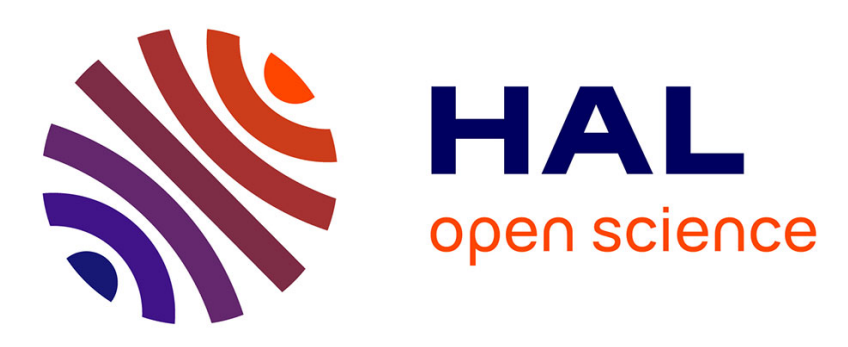

\title{
Aerogel Sintering: From Optical Glasses to Nuclear Waste Containment
}

Jean Phalippou, Philippe Dieudonné, A Faivre, Thierry Woignier

\section{To cite this version:}

Jean Phalippou, Philippe Dieudonné, A Faivre, Thierry Woignier. Aerogel Sintering: From Optical Glasses to Nuclear Waste Containment. Handbook of Sol-Gel Science and Technology Processing: Characterization and Applications, , pp.1949 - 1969, 2018, 978-3-319-32101-1. 10.1007/978-3-31932101-1_56. hal-01929789

\section{HAL Id: hal-01929789 \\ https://hal-amu.archives-ouvertes.fr/hal-01929789}

Submitted on 21 Nov 2018

HAL is a multi-disciplinary open access archive for the deposit and dissemination of scientific research documents, whether they are published or not. The documents may come from teaching and research institutions in France or abroad, or from public or private research centers.
L'archive ouverte pluridisciplinaire HAL, est destinée au dépôt et à la diffusion de documents scientifiques de niveau recherche, publiés ou non, émanant des établissements d'enseignement et de recherche français ou étrangers, des laboratoires publics ou privés. 


\title{
Aerogel Sintering: From Optical Glasses to Nuclear Waste Containment
}

\author{
Jean Phalippou, P. Dieudonné, A. Faivre, and Thierry Woignier
}

\section{Contents}

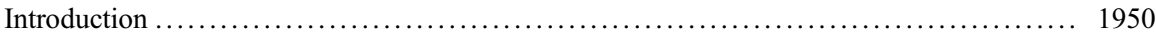

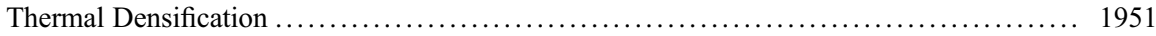

Pyrolysis of Organic Aerogels ........................................... 1951

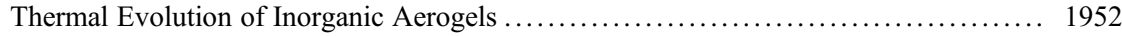

Densification by Isostatic Pressure ......................................... 1961

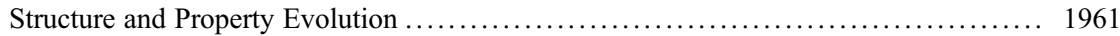

Textural Evolution .................................................... 1963

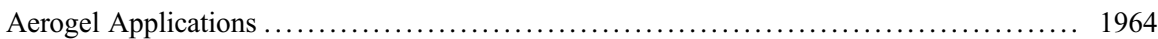

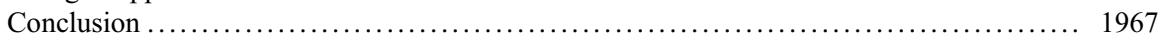

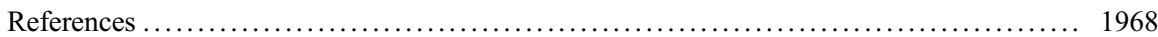

\begin{abstract}
Aerogels are ultraporous materials with a very low permeability. They exhibit high specific surface area but, due to their huge porous volume, their mechanical properties are quite poor. Aerogels belong to two main families: inorganic materials as silica, silicates, and a few aluminates and organic aerogels which are easily transformed into carbon aerogels by a simple pyrolysis thermal treatment. In this chapter, we mainly report experiments performed on alcohol-dried aerogels. Due to their broad range of porosity, aerogels can fit in very different applications: from analysis of cosmic dust to nuclear waste
\end{abstract}

J. Phalippou · P. Dieudonné

Laboratoire Charles Coulomb, Université Montpellier 2, Montpellier Cedex 5, France

A. Faivre

Laboratoire Charles Coulomb, Montpellier, France

T. Woignier $(\triangle)$

IMBE, CNRS, IRD, Aix Marseille Université, Avignon Université, Marseille, France

IRD - Campus Agro Environnemental Caraïbes, Le Lamentin, Martinique, France

e-mail: thierry.woignier@univ-montp2.fr 
containment glasses. Advantages of large porosity are sometimes used directly like in thermal and acoustic insulation, or in catalyzers, but a too high pore volume can also be a drawback like in glass precursor and host matrix. Fortunately, aerogel porosity can be tailored using sintering or room isostatic compression or eventually a combination of both methods. Knowledge in this area allows now to synthesize aerogels with a broad range of porosity and also a very broad range of texture.

\section{Introduction}

Aerogels are ultraporous materials with a very low permeability. They exhibit high specific surface area but, due to their huge porous volume, their mechanical properties are quite poor. The solid volume fraction may be as low as $0.13 \%$.

Aerogels are interesting because they can be obtained under monolithic shape. Their texture can be varied according to the details of gel synthesis but also by additional further treatments (thermal or mechanical) performed on samples as obtained after the drying step.

As we will see further, the porous volume of aerogels which is usually higher than $80 \%$ may be reduced and even eliminated using a thermal treatment. Up to now, aerogel is the only material whose porous volume can be varied over such a large domain. It is considered as a model to analyze the correlations between the porous volume and physical properties.

Aerogels are gels dried in an autoclave. The drying treatment consists in avoiding the capillary stresses occurring when the meniscus of liquid retreats inside the solid porous network (see Vol. 1, \ Chap. 34, "Nonhydrolytic Sol-Gel Technology" of this series). This process which requires to overpass the critical point of the liquid is named supercritical drying. Two liquids are advantageously used to perform supercritical drying. The first one and the most popular is alcohol. Most of the gels are prepared with alcohol, and the drying process is directly carried out on sample alcogels. Nevertheless, alcohol supercritical drying requires temperatures higher than $250{ }^{\circ} \mathrm{C}$. Some gels, mainly organic ones, do not withstand such high temperature. In that case, $\mathrm{CO}_{2}$ supercritical drying is preferred because the critical parameters are only $31{ }^{\circ} \mathrm{C}$ and $7.4 \mathrm{MPa}$. Moreover, $\mathrm{CO}_{2}$ is a much safer liquid than alcohol. However, $\mathrm{CO}_{2}$ supercritical drying needs a previous solvent exchange and the resulting aerogel is hydrophilic. This last property is often a drawback because air moisture can adsorb on the solid part of the aerogel. In this chapter, we mainly report experiments performed on alcohol-dried aerogels.

Aerogels belong to two main families. The inorganic materials are silica, silicates, and a few aluminates. Organic aerogels are those which are easily transformed into carbon aerogels by a simple pyrolysis thermal treatment. The most common organic aerogels are those made from resorcinol-formaldehyde, melamine-formaldehyde, and phenolic-furfural gels. 


\section{Thermal Densification}

\section{Pyrolysis of Organic Aerogels}

Pyrolysis of organic aerogels is performed to transform them into carbon aerogels. The aim of this treatment is not to densify the material but to change its chemical nature. The pyrolysis is performed under vacuum or under inert gas. At low temperatures, both DSC and TGA show that between $50{ }^{\circ} \mathrm{C}$ and $100{ }^{\circ} \mathrm{C}$, the material loses adsorbed water. The release of organic groups arises around $250{ }^{\circ} \mathrm{C}$ (Kuhn et al. 1998). Up to $600{ }^{\circ} \mathrm{C}$, a mass loss of about $40 \%$ occurs. In situ IR measurements performed at $600{ }^{\circ} \mathrm{C}$ (Fig. 1) as a function of time show that chemical groups $\mathrm{CH}_{2}$, $\mathrm{CH}$, and $\mathrm{OH}$ disappear while a small $\mathrm{CO}_{2}$ absorption band is observed. This last band indicates that pyrolysis produces $\mathrm{CO}_{2}$ gas. At the onset of heat treatment, this gas adsorbs on aerogel structure. For longer thermal treatment, $\mathrm{CO}_{2}$ desorbs and the IR band is no more observed. IR also demonstrates that $\mathrm{CC}$ stretching vibration of carbon ring located at $6.3 \mu \mathrm{m}$ assigned to resorcinol is observed during the entire isothermal treatment. However, the graphite structure establishes with time as evidenced by the increase of the vibration bands located at $6.3 \mu \mathrm{m}$ (superimposed with $\mathrm{C}-\mathrm{C}$ ) and $11.52 \mu \mathrm{m}$ which characterize the graphite structure. Obviously, the degree of graphitization of the carbon aerogel depends on the temperature, and full transformation requires temperatures higher than $1800-2000{ }^{\circ} \mathrm{C}$.

The evolution of the surface area of carbon aerogel pyrolyzed at temperatures ranging between 1050 and $2100{ }^{\circ} \mathrm{C}$ has been followed using small-angle X-ray

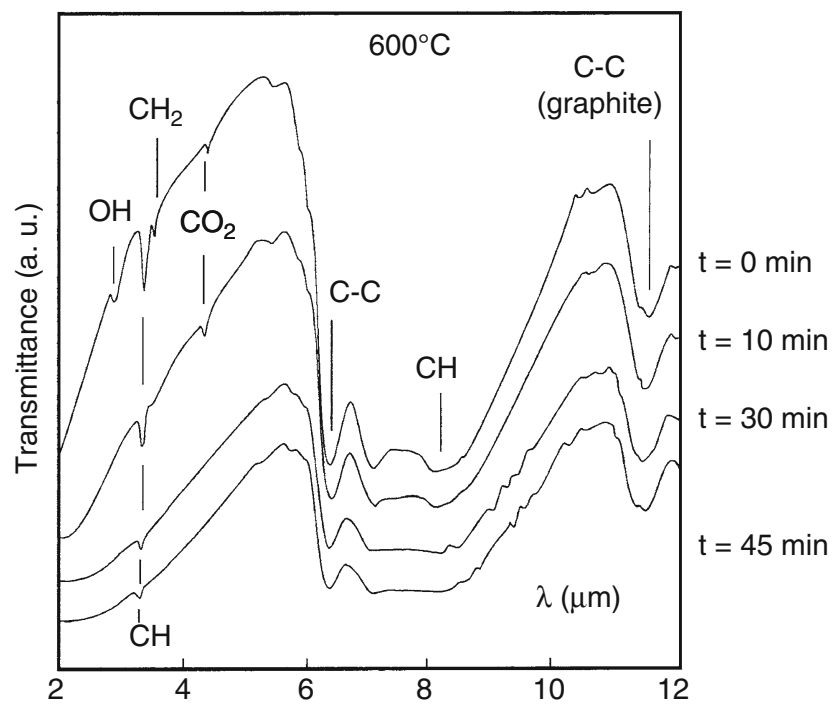

Fig. 1 In situ IR spectra of a resorcinol-formaldehyde aerogel for different times of pyrolysis thermal treatment carried out at $600^{\circ} \mathrm{C}$ 
scattering (SAXS) and $\mathrm{CO}_{2}$ adsorption performed at $0{ }^{\circ} \mathrm{C}$. Both measurements lead to different results because SAXS explores the whole porosity, while $\mathrm{CO}_{2}$ adsorption only analyzes accessible pores in the range of the largest micropores and mesopores. Only a part of the microporosity is accessible to $\mathrm{CO}_{2}$. Graphitization induces an increase of the microporous volume that can be considered as closed porosity. SAXS which allows an estimate of the gyration radius of micropores shows an enlargement of the mean size of micropores by a factor 2 between $1050{ }^{\circ} \mathrm{C}$ and $2100{ }^{\circ} \mathrm{C}$ (Reichenauer et al. 1998).

\section{Thermal Evolution of Inorganic Aerogels}

This paragraph mainly deals with silica aerogels obtained from alcohol supercritical drying process. These types of aerogels are the most usual. Thermal treatments allow to convert the aerogel into a fully dense silica glass. The density of silica aerogels depends on the preparation details. The lightweight aerogels exhibit a fractal geometry. They will be analyzed further.

Structural Evolution. The structural evolution of silica aerogels has been followed as a function of temperature using both near IR (Fig. 2a) transmission
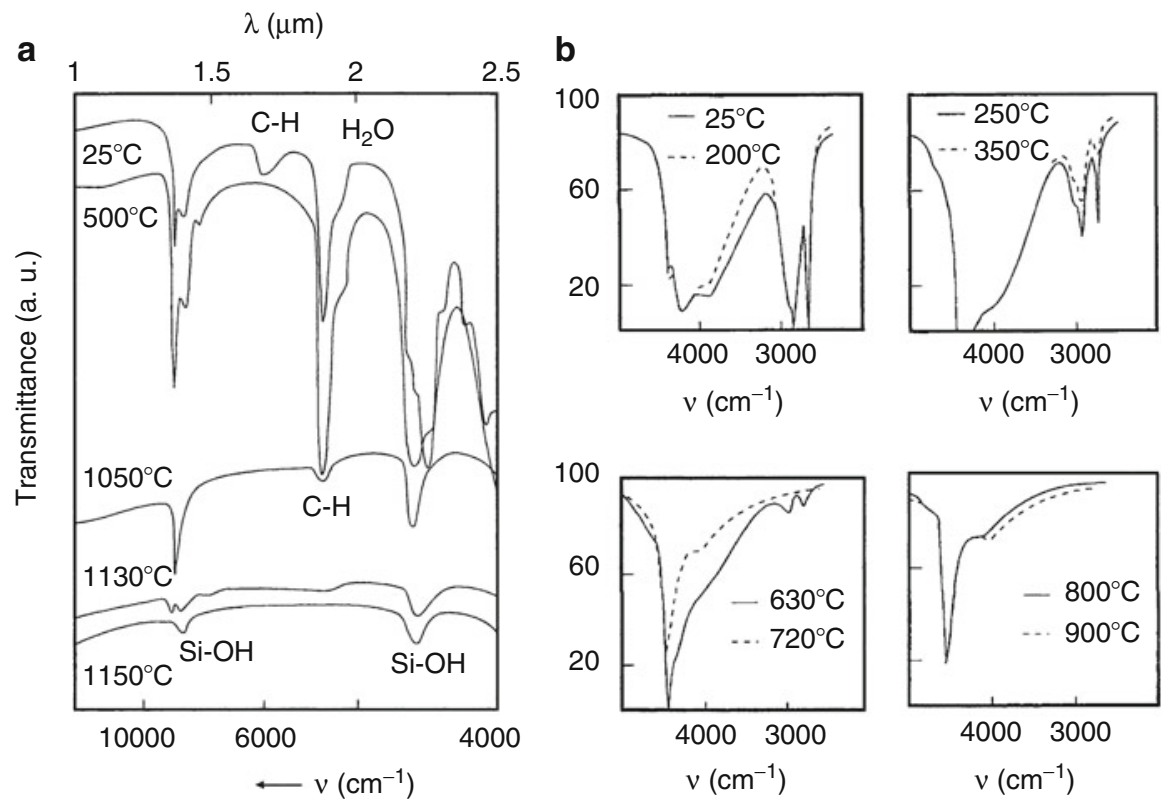

Fig. 2 (a) Near IR spectra of a silica aerogel obtained after heat treatment performed at several temperatures. (i) $25^{\circ} \mathrm{C}$ as obtained aerogel, (ii) $500^{\circ}$ after an oxidation treatment, and (iii) above $1000{ }^{\circ} \mathrm{C}$ in the sintering temperature range. (b) IR spectra of a silica aerogel as a function of temperatures including (i) the oxidation treatment (from $200{ }^{\circ} \mathrm{C}$ up to $350{ }^{\circ} \mathrm{C}$ ), (ii) the dehydration treatment $\left(630-720-800^{\circ} \mathrm{C}\right)$, and (iii) the onset of sintering $\left(900^{\circ} \mathrm{C}\right)$ 
and IR (Fig. 2b) spectroscopy (Woignier et al. 1990; Prassas et al. 1983). At low temperature, IR spectra indicate that $\mathrm{O}-\mathrm{CH}_{3}$ or $\mathrm{O}-\mathrm{C}_{2} \mathrm{H}_{5}$ groups resulting from the esterification reaction occurring within the autoclave react with oxygen. The oxidation reaction starts at about $250{ }^{\circ} \mathrm{C}$ and is achieved at $500{ }^{\circ} \mathrm{C}$. IR spectra also show that adsorbed water disappears first at low temperature. It is more difficult to remove hydroxyl groups. IR spectra of aerogels heat-treated at $900{ }^{\circ} \mathrm{C}$ still show the presence of silanol groups, $\mathrm{Si}-\mathrm{OH}$, remaining in the structure as observed by their stretching vibration band located at $3660 \mathrm{~cm}^{-1}$.

DTA and GTA (Prassas et al. 1983) confirm that the exothermic oxidation reaction induces between $300{ }^{\circ} \mathrm{C}$ and $600{ }^{\circ} \mathrm{C}$, a weight loss which is of $2-6 \%$ depending on the nature of the aerogels. Weight losses continue up to $1000{ }^{\circ} \mathrm{C}$ as a result of water escape. These water molecules are created by the condensation reaction of silanol groups.

Sintering by Viscous Flow. The evolution of sample dimension has been followed by dilatometric measurements performed at a heating rate of $3{ }^{\circ} \mathrm{C} / \mathrm{min}$. The aerogel shrinkage starts at about $500-1000{ }^{\circ} \mathrm{C}$. To obtain a fully dense material, the linear shrinkage gets higher than $50 \%$. Dilatometric measurements performed at several temperatures in the $900-1050{ }^{\circ} \mathrm{C}$ range as a function of time allow to evidence that the sintering occurs by viscous flow (Prassas et al. 1986).

Isothermal treatments in the sintering temperature range are shown in Fig. 3.

The sintering of aerogels has been analyzed using a model developed by Scherer (1977). This model describes the viscous flow sintering of amorphous material over a wide range of porosity $(0-95 \%)$. The porous material under analysis is considered as a cubic array of cylinders. The length of the cylinders is $\ell$ and the radius $r$. The sintering by viscous flow leads to a shrinkage of the length while the radius increases. The relative density $\rho_{\mathrm{a}} / \rho_{\mathrm{s}}$ where $\rho_{\mathrm{a}}$ is the bulk density and $\rho_{\mathrm{s}}$ the skeletal density is plotted as a function of a reduced time:

$$
K\left(t-t_{0}\right),
$$

where $t$ is the sintering time, $t_{0}$ is a fictitious time, and $K$ is a constant at a given temperature:

Fig. 3 Plots of bulk density against sintering time: $\diamond 980^{\circ} \mathrm{C}, \bullet 1005^{\circ} \mathrm{C}$, $\square 1050{ }^{\circ} \mathrm{C}, \Delta 1100^{\circ} \mathrm{C}$, $+1250{ }^{\circ} \mathrm{C}$

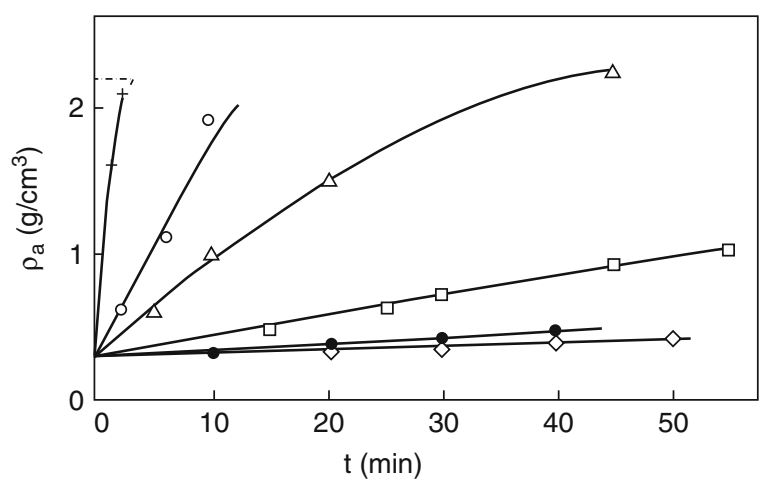


Fig. 4 Plot of the relative density $\rho_{\mathrm{a}} / \rho_{\mathrm{s}}$ versus the reduced time for a basecatalyzed silica aerogel treated at different temperatures:

$\cdot 1005^{\circ} \mathrm{C}, \square 1050^{\circ} \mathrm{C}, \Delta$ $1100{ }^{\circ} \mathrm{C}, \circ 1200^{\circ} \mathrm{C},+$ $1250^{\circ} \mathrm{C}$. The line corresponds to theoretical Scherer's model

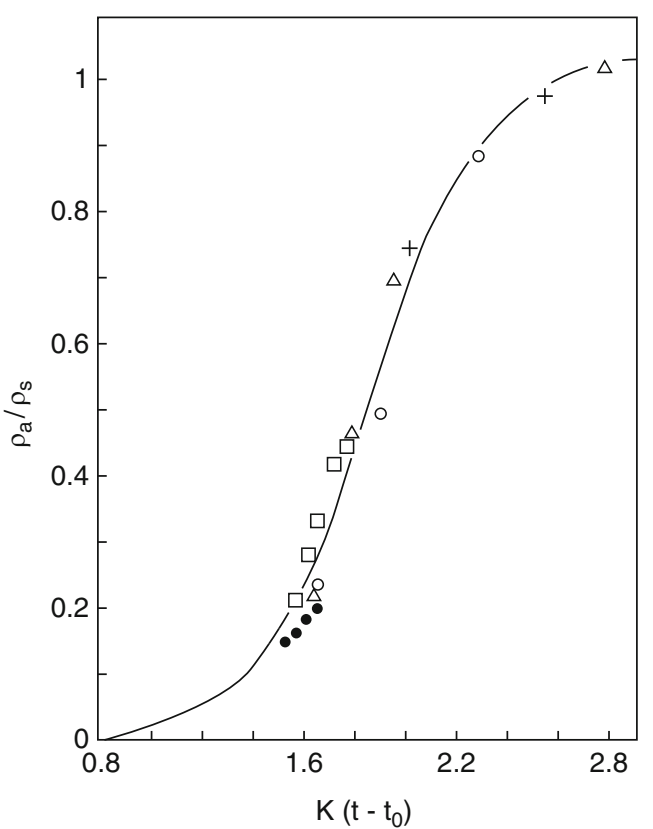

$$
K=\frac{\gamma}{\eta \ell_{i}}\left(\frac{\rho_{s}}{\rho_{i}}\right)^{1 / 3} .
$$

$\gamma$ is the surface energy and $\eta$ the viscosity. $\ell_{\mathrm{i}}$ and $\rho_{\mathrm{i}}$ refer to the length of the cell and to the initial bulk density of the aerogel, respectively.

Figure 4 shows that Scherer's model fits well on data obtained on aerogels for five isothermal sintering treatments. We must underline that the calculated $K$ constant depends on temperature as does the viscosity (Eq. 2). The activation energy associated to viscosity and estimated from sintering measurements is $368 \mathrm{~kJ} / \mathrm{mole}$. It is smaller than that usually found which is about $500 \mathrm{~kJ} / \mathrm{mole}$ for a silica glass having a hydroxyl content of $1300 \mathrm{ppm}$ in weight. The value of the activation energy depends on atmosphere but also on the hydroxyl content. In silica glass obtained from sintered aerogel, the hydroxyl content ranges between 3000 and 5000 ppm.

This water content plays an important role on the sintering kinetics. Lowering the water content increases the starting sintering temperature. When a silica aerogel is heated at a rate of $5{ }^{\circ} \mathrm{C} / \mathrm{min}$, full sintering occurs in a very short interval of temperature $\left(50-70{ }^{\circ} \mathrm{C}\right)$. Densification occurs at lower temperature (about $100{ }^{\circ} \mathrm{C}$ ) when aerogel contains water.

Because of the very fast sintering rate, a silica aerogel sample placed in a furnace in which the temperature is not homogeneous and varies between $900{ }^{\circ} \mathrm{C}$ and $1150{ }^{\circ} \mathrm{C}$ will give rise to a graded porosity material (Fig. 5). The top of the sample is fully dense while the bottom maintains an open porosity of $95 \%$. Obviously, a 
Fig. 5 Sintering in a furnace having a nonhomogeneous temperature leads to the material presented here. It is a composite material (glass/ porous) with a small transition porosity gradient

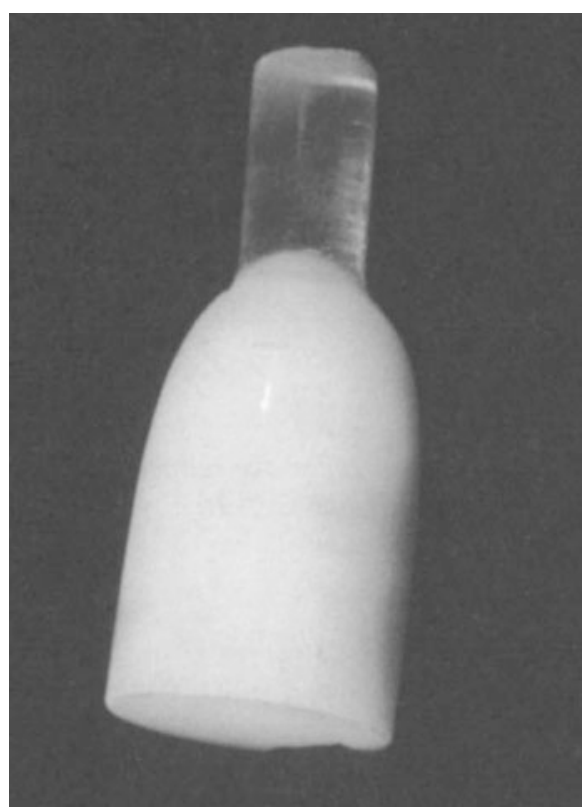

graded radial pore size distribution may also be obtained if a cylindrical sample is heated in such a way that its surface is at a higher temperature than that of the core.

For samples exhibiting a high water content, a foaming phenomenon occurs during sintering. Bubbles are due to water molecules which appear first in the core of the sample. During sintering, the first open pores to close are the ones located at the surface. Water molecules and air are trapped in the core solid network which is not totally densified. Bubbles grow and, with temperature increase, tend to expand. Light silica glass having a totally closed porosity can be prepared by this way.

To reduce the water content, a dehydration treatment is often performed before when the aerogel porosity is still open. Halide gases such as $\mathrm{CCl}_{4}, \mathrm{Cl}_{2}$, or $\mathrm{F}_{2}$ allow to remove hydroxyl groups. Remaining $\mathrm{Si}-\mathrm{Ci}$ or $\mathrm{Si}-\mathrm{F}$ groups are then reacted with $\mathrm{O}_{2}$ to avoid chloride of fluorine gases. Sintering is then advantageously performed under vacuum or under a helium flux. Because of the high diffusivity of helium, the collapse of closed pores is very fast (Sakaguchi 1995), and a full-dense transparent silica glass is obtained.

Textural Evolution. The textural evolution of aerogels with sintering is usually described using the specific surface area, the porous features (porosity, mean pore size distribution), or the solid-phase microstructure (fractal dimension, cluster, and primary particle sizes). To analyze the texture of porous material, the most wellknown technique is the adsorption (and desorption) of nitrogen (or $\mathrm{CO}_{2}$ ) as a function of relative pressure at $-196^{\circ} \mathrm{C}$. Specific surface area is obtained using BET theory (Brunauer et al. 1938) and pore size distribution using BJH theory (Barret et al. 1951). It must be mentioned here that such an experiment is not 
straightforward for light aerogels. The whole porous volume, $V_{P}\left(\mathrm{~cm}^{3} / \mathrm{g}\right)$, obtained from adsorption isotherm is far to correspond to that calculated using densities:

$$
V_{p}=\frac{1}{\rho_{a}}-\frac{1}{\rho_{s}},
$$

where $\rho_{\mathrm{a}}$ is the sample bulk density and $\rho_{\mathrm{s}}$ the skeletal density usually equal to $2.2 \mathrm{~g} / \mathrm{cm}^{3}$.

The reason of this discrepancy is mainly related to the dimensional changes occurring during the nitrogen adsorption measurement. During the experiment, the adsorbed nitrogen molecules induce a compressive stress. The associated strain affects the aerogel porosity. The strain depends on the aerogel elastic properties which play an important role on the measured values (Scherer et al. 1995a). The time-dependant length of the sample indicates that the aerogel relaxes slowly. Thus, pore size distributions are shifted toward smaller values. Measurements performed with different running times clearly evidence this effect (Reichenauer and Scherer 2001).

As sintering proceeds, the density of aerogel increases as well as its mechanical properties. At a given density, the aerogel is stiff enough to resist the induced stress, and the measured porous volume is equal to that calculated from densities.

Figure 6 displays the pore size distribution of a partially sintered aerogel having a starting density of $0.186 \mathrm{~g} / \mathrm{cm}^{3}$ (Dieudonné and Phalippou 1999). The three partially densified aerogels displayed in Fig. 6 have a density higher than $0.35 \mathrm{~g} / \mathrm{cm}^{3}$. For these samples, the whole porous volume measured using nitrogen adsorption isotherm corresponds to that calculated from densities. In that case, pore size distributions are meaningful. The mean pore size decreases as density increases. The

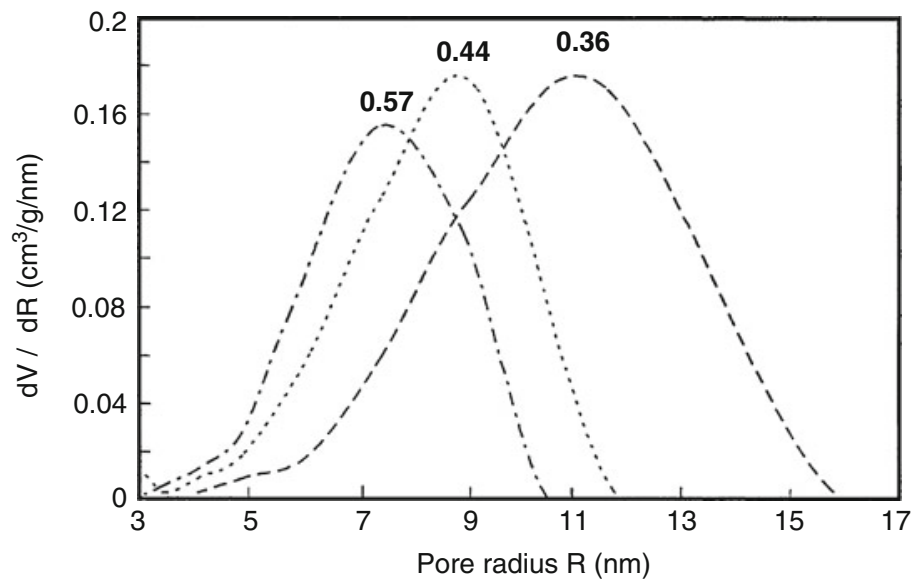

Fig. 6 Pore size distribution obtained by nitrogen desorption analysis of sintered base-catalyzed aerogels having a starting density of $0.186 \mathrm{~g} / \mathrm{cm}^{3}$. The measured porous volume of all samples (whose densities are indicated above curves) corresponds to that calculated from densities 
Table 1 Specific surface area evolution as a function of density for partially sintered aerogels

\begin{tabular}{l|l|l|c}
\hline Density & 0.36 & 0.44 & 0.57 \\
\hline $\mathrm{S}_{\mathrm{sp}}\left(\mathrm{m}^{2} / \mathrm{g}\right)$ & 332 & 320 & 266 \\
\hline
\end{tabular}

distribution spans from 4 to $15 \mathrm{~nm}$ for the lowest densified aerogel of this series. The size of the pores falls within the range of mesopores. Associated to densification, the specific surface area $S_{s p}$ decreases as indicated in Table 1.

However, the real surface area is expected to be higher than that measured. A part of the total surface is indeed lost at the neck between particles building the network, and nitrogen molecules cannot enter the micropores of smallest sizes.

To analyze the textural properties of aerogels, a more convenient method is the scattering of neutrons or X-ray at small angles. Such experiments do not induce textural evolution during characterization. The scattered intensity, $I(q)$, evolution with wave vector, $q$, depends on the details of the texture. Such experiments allow to explore a wide range of wave vector $\left(10^{-2}-1 \mathrm{~nm}^{-1}\right)$ as a function of scattering angle $\theta$ :

$$
q=\frac{4 \pi}{\lambda} \sin \frac{\theta}{2},
$$

where $\lambda$ is the wavelength of the incident beam.

Above the Guinier regime at very low $q$ values, we enter the Porod domain. For silica aerogels, this domain corresponds to $q>0.1 \AA^{-1}$. When the material does not show a fractal geometry and exhibits a smooth interface, the scattered intensity varies as (Porod 1982):

$$
I(q)=K q^{-4} .
$$

Porod showed that the surface area per volume unit, $S / V$, can be obtained from the following relation (Porod 1982):

$$
\frac{K}{Q}=\frac{1}{\pi f_{S} f_{P}} \frac{S}{V},
$$

where $f_{\mathrm{s}}$ and $f_{\mathrm{p}}$ are the volume fraction of solid and the volume fraction of pores, respectively. $K$ is experimentally determined from the curve of scattered intensity. It corresponds to the limit of $q^{4} I(q)$ when $q \rightarrow \infty$. $Q$ is known as the Porod invariant and is given by

$$
Q=\int_{0}^{\infty} q^{2} I(q) d q .
$$

Finally, the specific surface area can be calculated using the bulk aerogel density and the value of $S / V$ deduced from relation (6). 
Fig. 7 (a) Change in specific surface area estimated from SAXS measurements as a function of density and (b) variation of the mean chord length of solid and porous phase also obtained from SAXS measurements as sintering proceeds. The inset gives a schematic description of the chord lengths
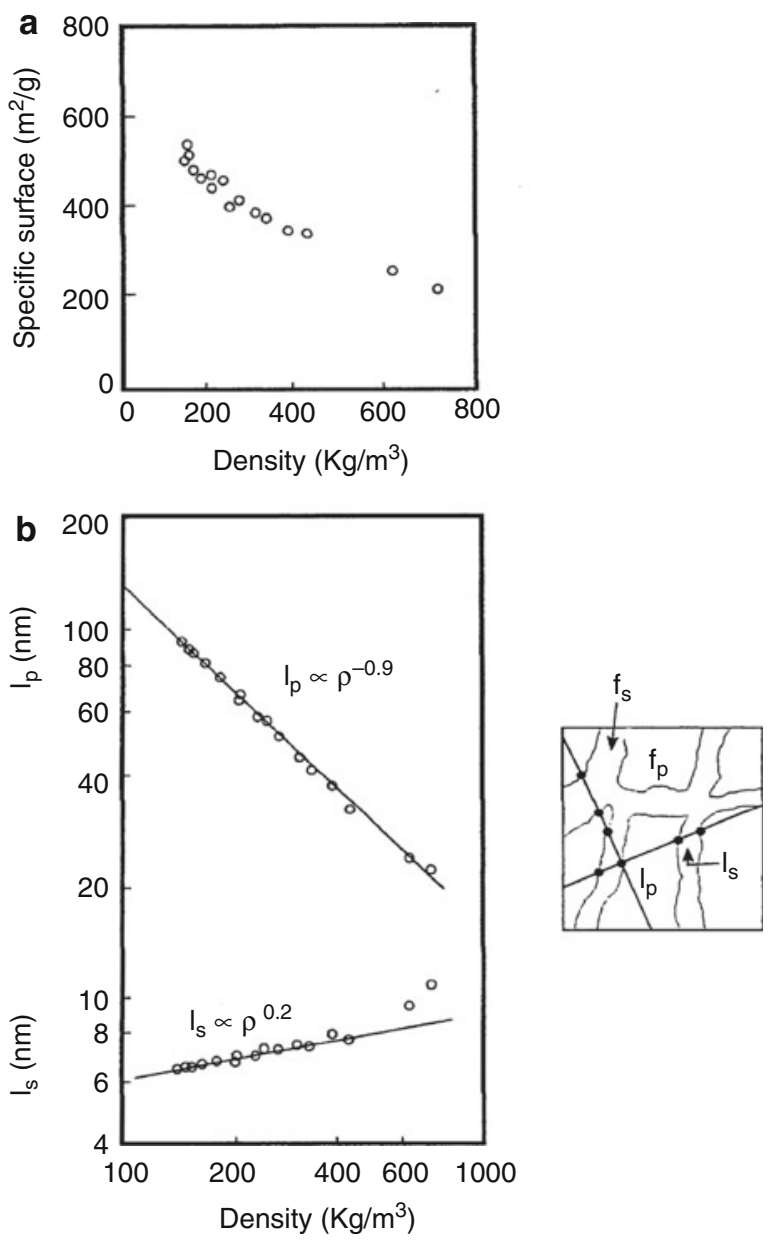

$$
S_{\mathrm{sp}}=\frac{S}{V} \frac{1}{\rho_{\mathrm{a}}} .
$$

The specific surface area evolves with densification (Fig. 7a). As expected, during sintering, it decreases with bulk sample density increase. From small-angle scattering experiments, it is also possible to extract details on the distribution of matter and pores within the material. A two-phase media model (Glatter 1982) allows to evaluate the mean chord length in the solid $\bar{\ell}_{\mathrm{S}}$ and in the porous phase $\bar{\ell}_{\mathrm{P}}$ :

$$
\bar{\ell}_{\mathrm{s}}=\frac{\bar{\ell}}{f_{\mathrm{p}}},
$$


Fig. 8 Scattered intensity oscillations around Porod's law

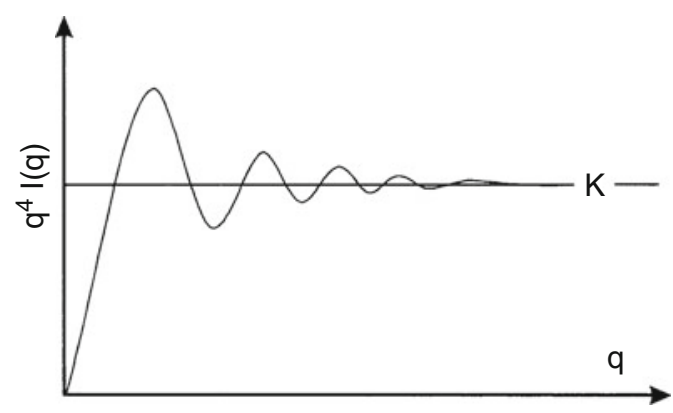

$$
\bar{\ell}_{\mathrm{p}}=\frac{\bar{\ell}}{f_{\mathrm{s}}}
$$

where $\bar{\ell}$ is the mean chord length related to Porod's invariant:

$$
\bar{\ell}=\frac{4}{\pi} \frac{Q}{K}
$$

The analysis of aerogel textural properties using this model applied to small-angle X-ray scattering measurements has been reported (Emmerling and Fricke 1992). Figure $7 \mathrm{~b}$ shows that the mean chord length in the porous phase varies as $\rho_{\mathrm{a}}^{-0.9}$, while the mean chord length in the solid varies as $\rho_{\mathrm{a}}^{-0.2}$. It is obvious that when the density approaches 1 , the porosity is about $50 \%$, and the mean chord lengths tend to the same value.

The scattered intensity may fluctuate around the Porod's law as schematically reported in Fig. 8. The oscillations are related to the shape, the mean size, and the distribution of the size of primary particles forming the aerogel skeleton.

The amplitudes of oscillation have been measured to be more and more pronounced when density increases (Fig. 9). The oscillations are also shifted to lower $q$ value. Such evolutions indicate that the particles grow during sintering. The starting aerogel can be modeled as an assembly of particles which are linked together to form cylinders arranged as Scherer model (Scherer 1977). In that case, the radius of the cylinder corresponds to that of the primary particles. The scattered intensity depends on the radius, $r$, and the radius distribution (of cylinders) (Guinier 1955). The fit of experimental curves with theoretical ones, assuming a Gaussian distribution of radii, allows an estimate of the mean radius variation with density. Figure 10 allows to compare the results of the evolution of the solid-phase dimension using both approaches. The two-phase media theory and the analysis of oscillations around Porod's law lead to about analogous evolution. The size of the solid phase increases with density (Dieudonné et al. 1988).

Light silica aerogels are of interest because they exhibit peculiar geometrical features. They have a similar geometry when observed under different lengths 
Fig. 9 Measured oscillations of SAXS intensity for initial $\left(0.186 \mathrm{~g} / \mathrm{cm}^{3}\right.$ density $)$ and partially sintered $(0.36$ and 0.57 ) base-catalyzed silica aerogels
Fig. 10 Particle size increase against density for a series of sintered base-catalyzed silica aerogels. $\bullet$ Estimated from the fit of oscillations of $\mathrm{I}(\mathrm{q}) \mathrm{q}^{4}$ with a theoretical Gaussian distribution of diameter of cylinders. $\bigcirc$ Estimated from the two-phase media theory
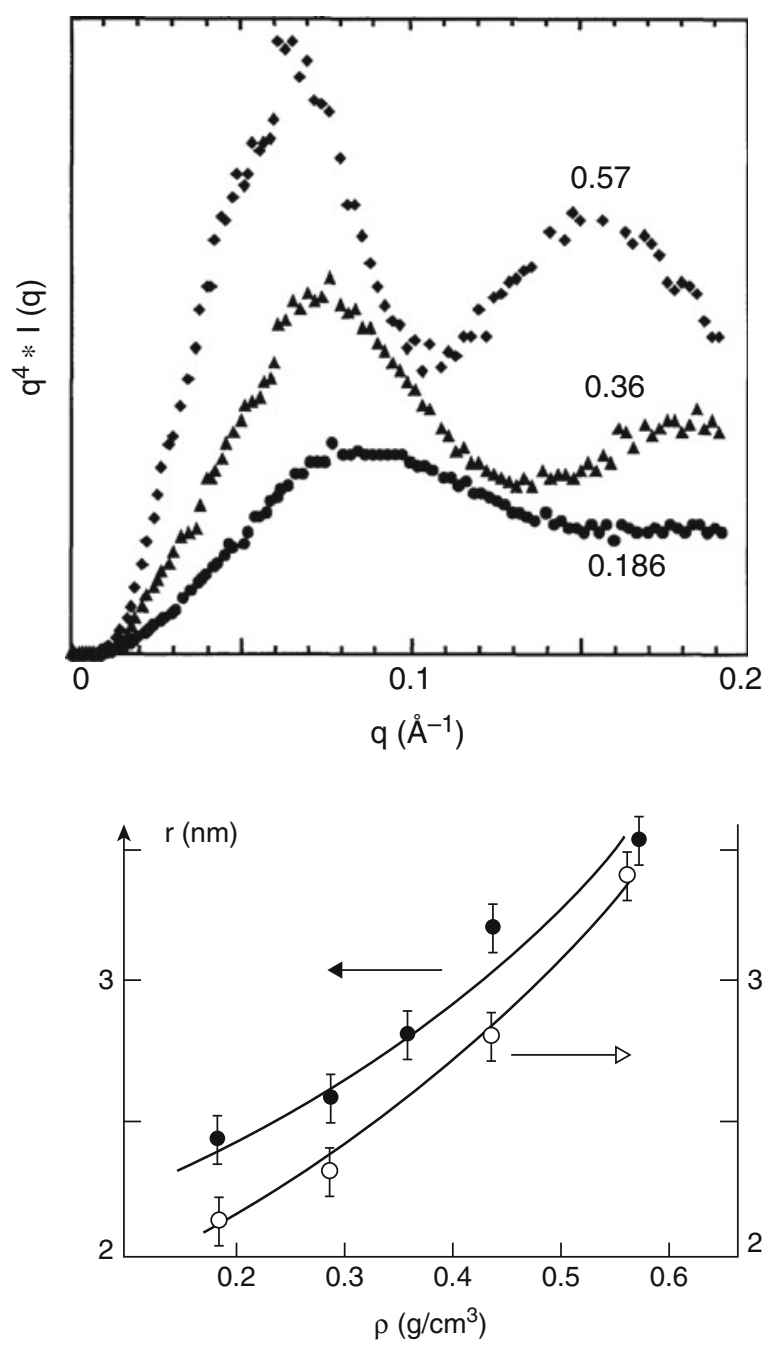

of scale. This self-similar geometry is the main property of fractal objects (Mandelbrot 1982).

Aerogels prepared under acidic conditions are composed of primary particles having a very small size. These particles aggregate to form clusters which stick together to build up the homogeneous network.

In this sort of aerogels, the cluster exhibits a fractal geometry as evidenced by small-angle X-ray scattering (Fig. 11). The fractal domain spans between the correlation length $\xi$ and the particle size a. The correlation length corresponds to the upper limit of the fractal domain. It roughly corresponds to the size of the fractal cluster. The fractal volume dimension is directly measured by the slope of the curve $\log I(q)$ versus $\log q$. Sintering of aerogels exhibiting a fractal geometry has been 
Fig. 11 SAXS

measurements obtained for a series of fractal partially densified aerogels. The sintering treatment is performed at $1000^{\circ} \mathrm{C}$ as a function of time. $\xi$ decreases while a increases (see arrows). The slope (fractal dimension) is drawn as guides for eyes

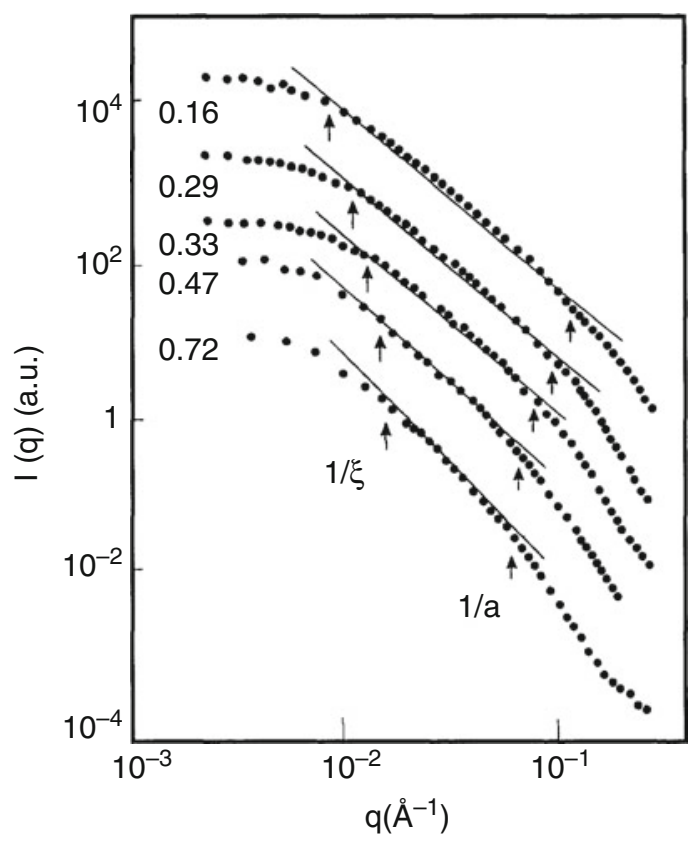

analyzed as a function of density for an isothermal treatment performed at $1000{ }^{\circ} \mathrm{C}$. The fractal dimension $D_{f}$ does not change significantly during the first stages of sintering. It is about 2.2-2.3. However, as shown in Fig. 11, the correlation length decreases when the particle size increases (Woignier 1984).

$\xi$ and $a$ evolutions with sintering have also been theoretically estimated from a scaling model describing fractal geometry (Jullien et al. 1995). This model predicts that the size of particle should vary as:

$$
a \propto \rho_{\mathrm{a}}^{D_{f} / 3\left(3-D_{f}\right)},
$$

while

$$
\xi \propto \rho_{\mathrm{a}}^{-1 / 3} .
$$

This model applies quite well to fractal aerogels having starting densities of about $0.3 \mathrm{~g} / \mathrm{cm}^{3}$. For lower-density aerogels, the fractal dimension increases as sintering proceeds, and a discrepancy between model and experiments arises.

\section{Densification by Isostatic Pressure}

\section{Structure and Property Evolution}

Elastic properties of aerogels submitted to uniaxial stress are quite striking. It has been demonstrated that the ultrasonic velocity decreases as the stress increases (Gross and Fricke 1992). This phenomenon is not due to the specific chemical 


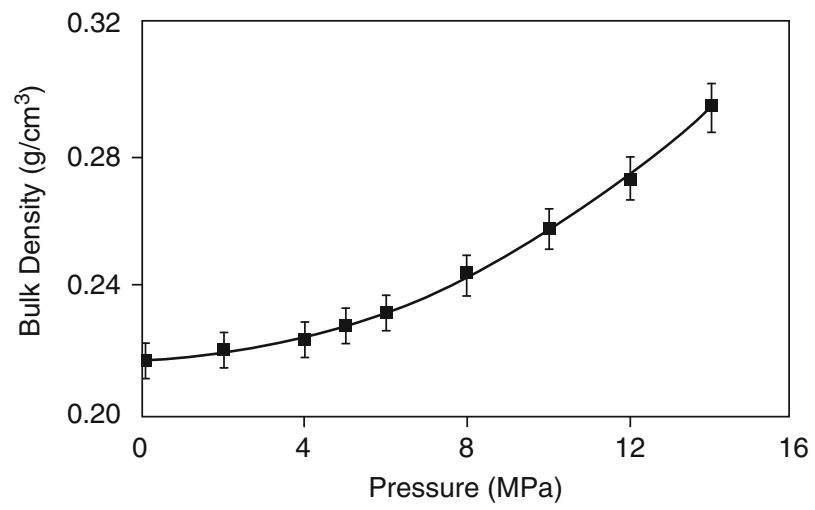

Fig. 12 Room temperature densification of a base-catalyzed silica aerogel as a function of isostatic pressure levels

nature of the network since it has been observed in a wide variety of aerogels. It is associated to the peculiar texture of aerogels whatever their chemical nature is. This effect is more conveniently evidenced with lightweight aerogels.

Due to their low pore size, evacuated aerogels can be pressurized using $\mathrm{Hg}$ liquid. The mercury which is a nonwetting liquid does not enter aerogel mesopores. The pressure applied to mercury compresses the aerogel skeleton and the network contracts. For low-pressure values, the strain due to external pressure returns to zero value with pressure release. This is a quite interesting experiment allowing to determine the bulk compression modulus of the aerogel (Woignier et al. 1997).

Above a threshold pressure value, the aerogel shrinkage is no more fully reversible, and a permanent densification is observed (Pirard et al. 1995; Duffours et al. 1996; Scherer et al. 1995b). An example of such a densification is shown in Fig. 12 for a base-catalyzed silica aerogel isostatically compressed at increasing pressure levels. This room temperature densification by compression depends on the texture and on the starting density of aerogels.

In addition, the irreversible shrinkage intensity depends on the chemical nature of the solid surface. IR measurements performed before and after compaction clearly indicate that this densification is related to a condensation reaction of silanols and an associated creation of water. A sharp increase in the IR absorption band located at $1620 \mathrm{~cm}^{-1}$ corresponding to deformation vibration of free water has indeed been evidenced (Duffours et al. 1996).

At the onset of densification, the elastic modulus decreases then increases for higher pressure levels (or densities). This effect has been associated to an initial damaging of the sample which is afterward counterbalanced by siloxane, $\mathrm{Si}-\mathrm{O}-\mathrm{Si}$, formation. These new links result from the condensation of silanols between vicinal solid chains getting in contact with pressure. Mechanical damage is evidenced by the rise of the internal friction measured in the range of $1 \mathrm{~Hz}$ using flexural dynamic 
Fig. 13 Specific surface area of base-catalyzed silica aerogels against density for compressed samples. $\Delta$ refers to SAXS measurements,

- refers to nitrogen adsorption measurements

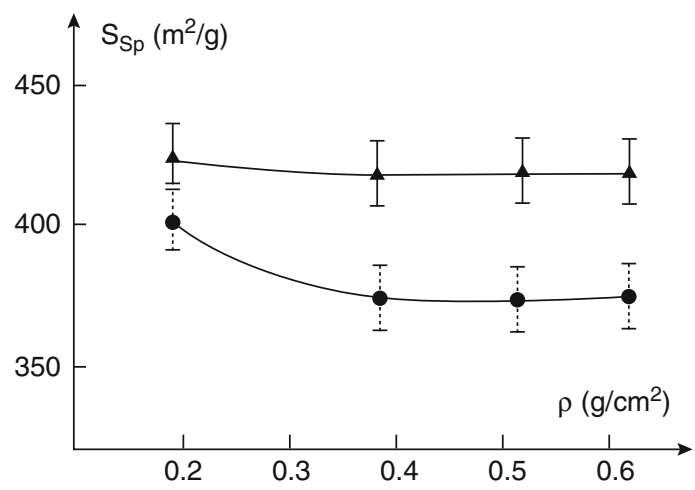

methods (Perin et al. 2004) and by the enlargement of the half width of Brillouin line in the GHz range (Calas et al. 1998).

\section{Textural Evolution}

The texture of compressed aerogels has been analyzed by classical nitrogen adsorption method using BET theory. Results show that the specific surface area $S_{s p}$ remains almost constant with densification by compression (Fig. 13).

The determination of specific surface area using small-angle X-ray scattering experiments in the Porod region leads to the same conclusion. This technique allows to explore the entire interface between solid and pore. The $S_{\mathrm{sp}}$ difference between the two techniques is attributed to the surface area lost in nitrogen adsorption measurement (Fig. 12).

The specific surface area is mainly linked to the particle size. Densification by compression acts on the cluster's connectivity but does not modify the size of primary particles. It is proposed that clusters interpenetrate as pressure increases. Oscillations around Porod's law (Fig. 14) confirm that with densification, the size of particle remains constant.

The pore size distribution of compressed aerogels has been determined using BJH theory. The mean pore size shifts toward small pore size as density increases. On the other hand, the pore size distribution narrows. The pores of the aerogel become more monosized (Fig. 15). These results can be compared with the pore size distribution of aerogels thermally sintered and having the same density. Compression is assumed to collapse preferentially the largest pores (Pirard et al. 1995), while in the case of thermal sintering, the smallest pores are first affected (Woignier et al. 1992).

Base-catalyzed silica aerogels exhibiting a fractal geometry have been investigated using SAXS. Spectra demonstrate that at the onset of compression, the particle size remains constant with densification, while the correlation length decreases. That means that at the onset of densification by compression, the interpenetration of 
Fig. 14 Oscillations around Porod's law for compressed densified aerogels showing that mean particle size remains constant

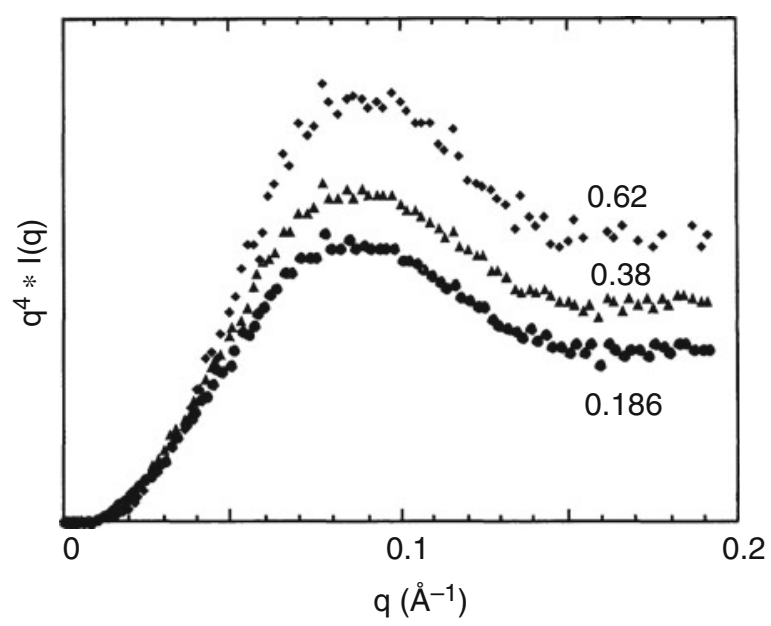

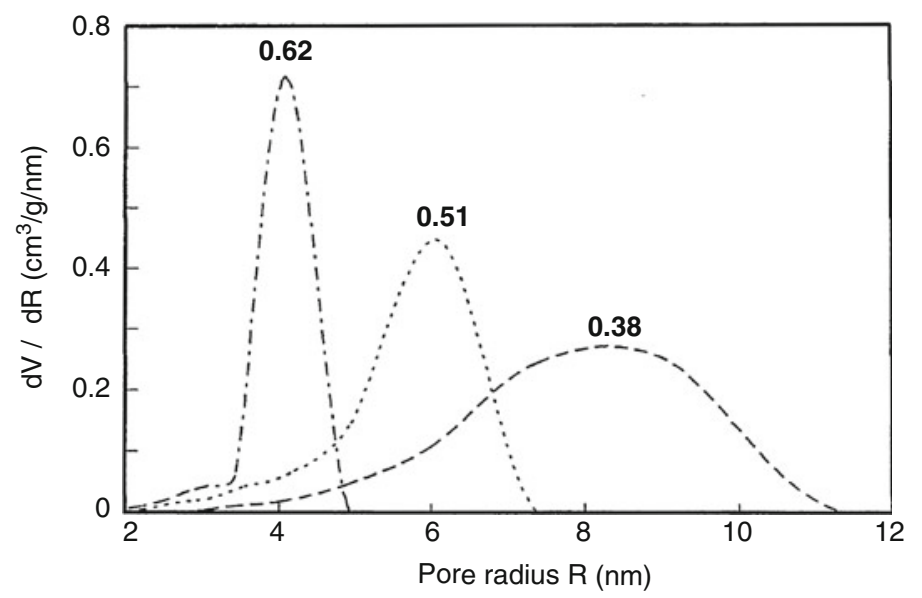

Fig. 15 Pore size distribution of aerogels densified by compression obtained from nitrogen desorption measurements

clusters reduces the fractal domain, while the fractal dimension (here equal to 2.2) and the primary particle size are unaltered Beurroies et al. (1998) (Fig. 16).

\section{Aerogel Applications}

Most of aerogel applications are associated to the high porosity of these specific materials. The main applications have been previously reported in excellent reviews (Fricke and Emmerling 1992; Hrubesh 1998). 


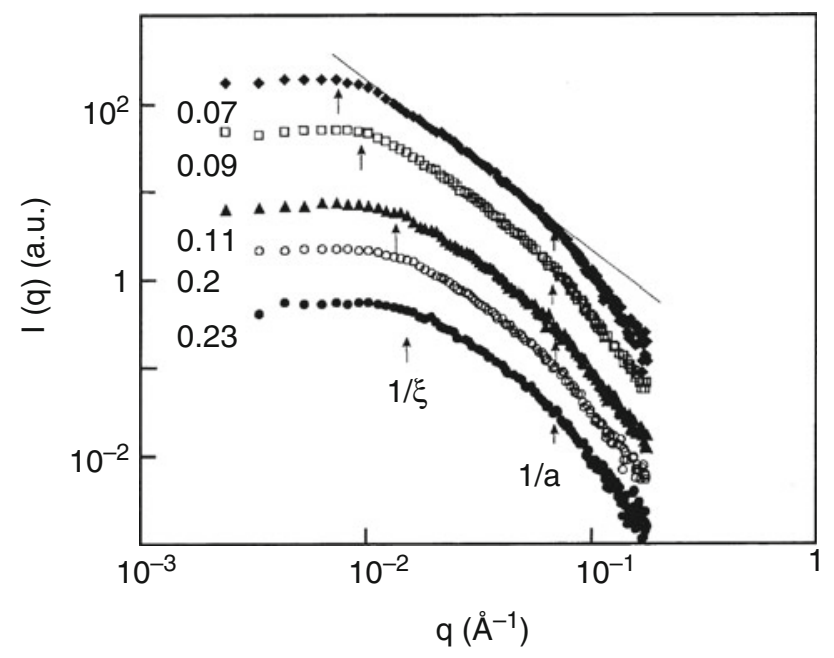

Fig. 16 SAXS measurements for light base-catalyzed silica aerogels exhibiting a fractal geometry

As prepared, aerogels which are obtained monolithic and which are transparent take applications in nuclear physics. Aerogels are used in Cherenkov detectors for charged relativistic particles such as pions, protons, or mesons. The velocity of these particles is higher than that of light in the aerogels. Entering the aerogel, the particle produces an electromagnetic shock wave (Cherenkov radiation) forming a cone with the axis in the direction of particle and whose angle and wavelength give information about the particle velocity. Aerogel Cherenkov counters allow the separation of $\pi$ and $\mathrm{K}$ mesons with 0.6-1.5 GeV/C momentum (Buzykaev et al. 1998). The aerogel refractive index for such application is in the range 1.018-1.05. According to the rough relation between the refractive index and the bulk density:

$$
n=1+0.21 \rho_{\mathrm{a}}
$$

Aerogels having densities between 0.085 and $0.24 \mathrm{~g} / \mathrm{cm}^{3}$ are required. Gels catalyzed with a basic or HF aqueous solution give rise to suited highly transparent aerogels.

Analogous aerogels are also used in space research as a capture medium for cosmic dusts. These hypervelocity particles enter the fine structure of the aerogel which dissipates their kinetic energy. Consequently, particles having a few micron size can be captured intact and easily located within the transparent aerogel (Tsou 1995).

$\mathrm{Al}_{2} \mathrm{O}_{3}, \mathrm{TiO}_{2}, \mathrm{ZrO}_{2}, \mathrm{MgO}$, and binary oxide gels exhibiting catalytic properties have been elaborated. They have been supercritically dried to give rise to ultraporous material with surface areas higher than $500 \mathrm{~m}^{2} / \mathrm{g}$. Catalytic properties have been listed in Pajonk's review (Pajonk 1991). It must be mentioned that densification of aerogels by compression, previously described (see section "Densification by 
Isostatic Pressure"), could also be used to enhance catalytic properties. Since for a given mass of aerogel the specific surface area remains constant, the densification should increase the reactive surface per volume unit of aerogel. However, a decrease in the permeability value is anticipated.

Transparent silica aerogels find applications in the field of windows having a low thermal conductivity (Butter et al. 1986). The aerogels have a high porosity, but their pore size is always smaller than $50 \mathrm{~nm}$. As a consequence, the convective heat transport is negligible. Silica skeleton is moreover a bad conductive medium. The conductivity of monolithic silica aerogel measured in air is $0.013 \mathrm{~W} /(\mathrm{m}-\mathrm{K})$ at room temperature. Comparatively, the silica glass has a conductivity of $1.4 \mathrm{~W} /(\mathrm{m}-\mathrm{K})$, i.e., about 100 times higher. The transmission of transparent silica aerogel is appreciable $(84 \%)$ compared to that of window glass $(89 \%)$. Because the radiative heat transport depends on temperature and because silica is transparent between 2 and $5 \mu \mathrm{m}$, an opacifier such as black carbon must be added to maintain thermal insulation properties up to $200{ }^{\circ} \mathrm{C}$. With $15 \%$ in weight of carbon soot, the thermal conductivity of the composite aerogel remains about $0.02 \mathrm{~W} /(\mathrm{m} . \mathrm{K})$ in the $25-200{ }^{\circ} \mathrm{C}$ temperature range. These aerogels which are no longer transparent are only used as thermal insulators. Obviously, in this temperature range, the best aerogel insulator is carbon aerogel which is opaque but whose thermal conductivity at room temperature is of 10-12 $\times 10^{-2} \mathrm{~W} /(\mathrm{m} \cdot \mathrm{K})$. Polyurethane-based aerogels are prepared for similar purpose (Biesmans et al. 1998). Note that thermal insulation properties do not necessarily require monolithic samples. In many applications, granules or spheres having a diameter of a few millimeters are more suitable because of their easier handling.

Sound velocity, $V$, can be lower in aerogel than in air. The aerogel acoustic impedance $\left(\rho_{\mathrm{a}} V\right)$ may be tailored to play the role of an impedance-matching medium for ultrasonic sensor systems. An enhancement of the yield of acoustic transductor is anticipated. As an example for frequencies in the range of $100 \mathrm{kHz}$, a material having a specific impedance of $10 \mathrm{~kg} / \mathrm{m}^{2} \cdot \mathrm{s}$ is required. For such an application, the thickness of the aerogel layer must be close to $\lambda / 4$, corresponding to a few millimeters. However, a perfect mechanical contact between the transductor and the aerogel is difficult to achieve (Gronauer and Fricke 1986; Gibiat et al. 1995).

As previously evoked in this chapter, silica aerogels can be fully densified by thermal sintering and transformed into silica glass at temperatures close to the glass transition. Since chemical starting compounds (alkoxides) are of excellent purity, resulting glasses show good optical properties. Their refractive index can also be modified by including some other elements such as boron or phosphorus (Woignier et al. 1990).

Organic aerogels remain porous but pyrolysis transforms them into carbon aerogels whose structure approaches graphite as the pyrolysis time and temperature increase. Carbon aerogels with specific surface areas within the range 400-1000 $\mathrm{m}^{2} / \mathrm{g}$ and having an electrical conductivity of a few $\Omega / \mathrm{cm}$ find applications in the field of electrochemistry (Salinger et al. 1998). Two layers of carbon aerogels separated by a porous electrical insulating membrane are, respectively, connected to nonporous electrodes (mainly dense carbon) of an electric cell containing a strong aqueous 
electrolyte $\left(\mathrm{H}_{2} \mathrm{SO}_{4}\right.$ or $\left.\mathrm{KOH}\right)$. Applying a voltage between electrodes the cations and anions move versus electrodes, an electrochemical double layer is created within the carbon aerogel which plays the role of a supercapacitor. This system allows to have a high capacity in a small volume. The capacity has been measured to be up to $50 \mathrm{~F}$ per cubic centimeter. Supercapacitors are commonly used to deliver energy during short power interruption. The charge time of supercapacitors is in the range of $10 \mathrm{~s}$. The number of charges and discharges is virtually unlimited.

Aerogels which are not fully sintered or aerogels isostatically compressed are named partially densified aerogels (PDA). Their porous volume may be tailored to give rise to a material having suitable mechanical properties. As a consequence, aerogels partially densified (by thermal, compression-thermal treatment) can withstand capillary forces when wetted by a liquid. If the liquid contains salts of interest, the PDA plays the role of a host material. Guest molecules are deposited on the surface of the skeleton as the liquid is further evaporated. The optimization of the mean pore size and the pore size distribution is needed to facilitate a homogeneous dispersion of doping molecules within the texture.

Note that if sintering is carried out inside a gradient furnace, graded porous volume with graded pore size is obtained. Doping will result in a graded property material. Additionally, the doped material may be completely densified by a further sintering thermal treatment.

Because of their high chemical durability, silica glasses are good candidates for nuclear waste management. However, the production of silica glass by a conventional melting process requires temperature higher than $2000{ }^{\circ} \mathrm{C}$. Fortunately, silica aerogels are fully sintered using a thermal treatment of $1050-1100{ }^{\circ} \mathrm{C}$ for only $15 \mathrm{~min}$. So, sintered silica aerogels also are good matrices for the confinement of actinides. Partially densified aerogels are soaked in solution containing an element (e.g., neodymium) simulating nuclear wastes. After the soaking treatment, host matrix is dried and then sintered. The resulting material is a composite constituted by $\mathrm{Nd}_{2} \mathrm{O}_{3}$ crystals embedded into a silica matrix. The dissolution rate of such a composite in water at $100{ }^{\circ} \mathrm{C}$ is $10^{2}$ times lower than that of the nuclear borosilicate glasses (Woignier et al. 1998).

\section{Conclusion}

Due to their broad range of porosity, aerogels can fit in very peculiar and very different applications: from analysis of cosmic dust to nuclear waste containment glasses. Advantages of large porosity are sometimes used directly like in thermal and acoustic insulation, or in catalyzers, but a too high pore volume can also be a drawback like in glass precursor and host matrix. Fortunately, as it has been described in this chapter, aerogel porosity can be tailored using sintering or room isostatic compression or eventually a combination of both methods. Knowledge in this area allows now to synthesize aerogels with a broad range of porosity and also a very broad range of texture. 
The counterpart of aerogel large porosity is their poor mechanical properties. A "material" can be defined as a "solid designed for an application," and applications can only be fulfilled if the mechanical features of the "material" are acceptable. Certainly, one of the new challenges of the aerogel research field concerns the improvement of their mechanical behavior.

Another promising ability of aerogels is their doping to create new materials and composites. The aerogel can play the role of host material for guest molecules showing catalytic, optical, magnetic properties. This field of applications is actually not really explored. It is certainly very interesting to synthesize giving hybrids materials or nanocomposites such as doped glasses, glass-ceramics, nanocomposite gel polymer, gel-metal, etc.

And finally, it must be added that only silica and organic aerogels have been discussed here, but several other types of aerogels are under investigation.

Acknowledgments The authors would like to thank the editors of Journal of Non-Crystalline Solids, Journal of Sol-Gel Science and Technology, Journal of Material Science for their permission to publish figures here reported.

\section{References}

Barret EP, Joyner LG, Halenda PP. The determination of pore volume and area distribution in porous substances. I. Computations from nitrogen isotherms. J Am Chem Soc. 1951;73:373-80.

Beurroies I, Duffours L, Delord R, Woignier T, Phalippou J. Fractal geometry change induced by compression - densification. J Non Cryst Solids. 1998;2421:38-44.

Biesmans G, Randall D, Français E, Perrut M. Polyurethane-based organic aerogels thermal performance. J Non Cryst Solids. 1998;225:36-41.

Brunauer S, Emmet P, Teller E. Adsorption of gases in multimolecular layers. J Am Ceram Soc. 1938;60:309-19.

Butter D, Caps R, Heinemann U, Hummer E, Kadur A, Schenerpflug P, Fricke J. Thermal conductivity of $\mathrm{SiO}_{2}$ aerogels tiles. In: Fricke J, editor. Aerogels, Berlin: Springer; 1986, p. $104-109$.

Buzykaev AR, et al. Aerogel Cherenkov counters with wavelength shifters and micro-channel plate photo-tubes. J Non Cryst Solids. 1998;225:381-4.

Calas S, Levelut C, Woignier T, Pelous J. Brillouin scattering study of sintered and compressed aerogels. J Non Cryst Solids. 1998;225:244-8.

Dieudonné P, Phalippou J. Textural properties of densified aerogels. J Sol-Gel Sci Technol. 1999;14:1-8.

Dieudonné P, Delord P, Phalippou J. Small angle X-ray scattering of aerogel densification. J Non Cryst Solids. 1988;225:220-5.

Duffours L, Woignier T, Phalippou J. Irreversible volume shrinkage of silica aerogels under isostatic pressure. J Non Cryst Solids. 1996;194:283-90.

Emmerling A, Fricke J. Small angle scattering and the structure of aerogels. J Non Cryst Solids. 1992;145:113-20.

Fricke J, Emmerling A. Aerogels. J Am Ceram Soc. 1992;75(8):2927-36.

Gibiat V, Lefeuvre O, Woignier T, Pelous J, Phalippou J. Acoustic properties and potential applications of silica aerogels. J Non Cryst Solids. 1995;86:244-55.

Glatter K. Small angle X ray scattering. London: Academic; 1982.

Gronauer M, Fricke J. Acoustic properties of microporous $\mathrm{SiO}_{2}$ aerogels. Acoustica. 1986;59:177-85. 
Gross J, Fricke J. Ultrasonic velocity measurements in silica, carbon and organic aerogels. J Non-Cryst Solids. 1992;145:217-22.

Guinier F. Small angle scattering of X-rays. New York: Wiley; 1955.

Hrubesh LW. Aerogel applications. J Non Cryst Solids. 1998;225:335-42.

Jullien R, Olivi-Tran N, Hasmy A, Woignier T, Phalippou J, Bourret D, Sempéré R. Scaling theory and numerical applications of aerogel sintering. J Non Cryst Solids. 1995;188:1-10.

Kuhn J, Brandt R, Mehling H, Petricevic R, Fricke J. In situ infrared observation of the pyrolysis process of carbon aerogels. J Non Cryst Solids. 1998;225:58-63.

Mandelbrot BB. The fractal geometry of nature. New York: Freeman; 1982.

Pajonk GM. Aerogel catalysts. Appl Catal. 1991;72:217-66.

Perin L, Faivre A, Calas-Etienne S, Woignier T. Nanostructure damage associated to isostatic compression of silica aerogels. J Non Cryst Solids. 2004;333:68-73.

Pirard R, Blacher S, Brouers F, Pirard JP. Interpretation of mercury porosimetry applied to aerogels. J Mater Res. 1995;10(8):2114-9.

Porod G. General theory. In: Glatter O, Kratky O, editors. Small angle X-ray scattering, vol. 2. London: Academic; 1982. p. 17-51.

Prassas M, Phalippou J, Zarzycki J. Evolution structurale et texturale des gels monolithiques de silice en fonction de la température. Glastech-Ber. 1983;56K:542-7.

Prassas M, Phalippou J, Zarzycki J. Sintering of monolithic silica aerogels. In: Hench LL, Ulrich DR, editors. Science of ceramic chemical processing, vol. 17. New York: Wiley; 1986. p. $156-67$.

Reichenauer G, Scherer GW. Nitrogen sorption in aerogels. J Non Cryst Solids. 2001;285:167-74.

Reichenauer G, Emmerling A, Fricke J, Pekala RW. Microporosity in carbon aerogels. J Non Cryst Solids. 1998;225:210-4.

Sakaguchi S. Behavior of closed pores formed in consolidation process for silica soot precursor. J Non Cryst Solids. 1995;189:43-9.

Salinger R, Fisher U, Herta C, Fricke J. High surface area carbon aerogels for supercapacitors. J Non Cryst Solids. 1998;225:81-5.

Scherer GW. Sintering of low density glasses: I. Theory. J Am Ceram Soc. 1977;60(5-6):236-40.

Scherer GW, Smith DM, Stein D. Deformation of aerogels during characterization. J Non Cryst Solids. 1995a;186:309-15.

Scherer GW, Smith DM, Qiu X, Anderson JM. Compression of aerogels. J Non Cryst Solids. 1995b;186:316-20.

Tsou P. Silica aerogel captures cosmic dust intact. J Non-Cryst Solids. 1995;186:415-27.

Woignier T. Contribution à l'obtention de verres par la voie sol-gel. PhD, Montpellier, 1984.

Woignier T, Phalippou J, Prassas M. Glasses from aerogels. J Mater Sci. 1990;25:3118-26.

Woignier T, Quinson JF, Pauthe M, Repellin-Lacroix M, Phalippou J. Evolution of the porous volume during the aerogel-glass transformation. J Phys IV. 1992;C2:123-6.

Woignier T, Duffours L, Beurroies I, Phalippou J, Delord P, Gibiat V. Plasticity in aerogel. J Sol-Gel Sci Technol. 1997;8:789-94.

Woignier T, Reynes J, Phalippou J, Dussossoy JL, Jacquet-Francillon N. Sintered silica aerogel: a host matrix for long life nuclear wastes. J Non-Cryst Solids. 1998;225:353-7. 